\title{
A CORTIÇA COMO DESAFIO PARA NOVOS USOS NO DESIGN
}

Lucy Niemeyer

UNIDCOM-IADE-U Creative University

lucy.niemeyer@gmail.com

William Cantú

IADE-U Creative University

williamafonsoc@gmail.com

Resumo: A cortiça é um material natural completamente autossustentável e tem um grande potencial a ser explorado como matéria prima. A síntese da pesquisa aqui apresentada intenta difundir a amplitude de aplicação da cortiça e estimular os designers a explorarem as suas possibilidades de experimentação e adoção em produtos na área do Design. As suas características únicas fazem com que seja adequada a diversas situações de uso. A sua utilização traz possibilidades positivas tanto sociais, como econômicas, quanto estéticas. Com os avanços da pesquisa científica, procura-se aprofundar o conhecimento desse material e identificar como o ele pode ser usado em especial no Design, e, de modo inovador, elevar a qualidade da produção de bens e trazer benefícios para a sociedade e o ambiente.

Palavras-chave: cortiça, design, sustentabilidade, inovação.

Abstract: Cork is a completely self-sustaining natural material and has a great potential to be adopted as raw material. The synthesis of the research presented here intends to spread the range of application of cork and encourage designers to explore its experimentation and to adopt cork in Design products. Its unique characteristics make it suitable for various uses. Cork enhances positive social, economic and aesthetic opportunities. The advances in scientific research intend to deepen the knowledge of this material and identify how it can be better used, in particular in Design, and, in an innovative way, to heighten the production of goods and bring benefits to society and to environment.

Keywords: cork, design, sustainability, innovation. 


\section{INTRODUÇÃO}

Este trabalho apresenta uma síntese da investigação sobre matérias-primas sustentáveis, incidindo sobretudo sobre a temática da cortiça bem como a utilização deste material no design. O objetivo é incentivar e promover o uso da cortiça como matéria-prima com valores ecológicos e sustentáveis, considerando a relevância de estudos com este propósito e com essa matéria em especial. Podemos observar que "no futuro muitas das matérias-primas só vão estar disponíveis em quantidades limitadas, a sustentabilidade é a palavra chave para uma progressão da consciência humana. A consciência ambiental e a predisposição para pensar nos ciclos de materiais, nomeadamente, 0 uso de materiais e de métodos de produção ambientalmente ecológicos é desejável. “ (Fialho, 2014).

\section{DESENVOLVIMENTO}

Segundo Mestre (2008, p. 33), a cortiça é uma matéria-prima versátil, capaz de se adaptar a diferentes processos tecnológicos de transformação e tem diferentes aplicações. O setor produtivo está à procura de materiais cujo foco seja a sustentabilidade e em produtos que possam transmitir os valores da ecologia. A cortiça é, sendo assim, uma matéria natural que se adequa nestes parâmetros. Designam-se materiais sustentáveis aqueles que proporcionam benefícios ambientais, sociais e econômicos ao mesmo tempo que protegem a saúde pública e o ambiente durante todo o seu ciclo de vida, desde a extração desses materiais até ao fim do seu ciclo de vida.

Com o intuito de inovar e procurar dar novas respostas à utilização da cortiça, surge em Portugal um modelo único de estudo desse material. É através da Professora Cristina Veríssimo e do Professor Manuel Couceiro que surge o Cork Workshop - new uses in architecture, que, em parceria com a Faculdade de Arquitetura da Universidade de Lisboa (FAUL) e a Dalhousie, no Canadá, alunos abordam a cortiça através de um novo ponto de vista mais crítico e experimental. É, além das visitas de estudo e da observação de campo, a prototipagem com o próprio material que permite compreender como o mesmo pode se comportar em diversas situações. Passando por testes com os mais diferentes tipos de cortiça produzida e acompanhados por professores e técnicos da cortiça, os alunos procuram estudar e desenvolver meios de trabalhar com essa matéria, focando em aspetos como a inovação, sustentabilidade, versatilidade e projeto. Aliam-se nesse processo de estudo diversas áreas como o Design, a Arquitetura, a Engenharia, a Biologia, a Química e a Física, dando os respetivos contributos. Esse projeto de estudo acontece anualmente em Lisboa (FAUL). Durante um ciclo de três anos onde são abordadas três temáticas que definem os eixos anuais de estudo respetivos, sendo os mesmos: ano 1 - cortiça natural, ano 2 - cortiça e materiais compósitos e ano 3 - cortiça e as novas tecnologias. Ao fim de três anos um ciclo do projeto se reinicia e novos estudos são realizados procurando, já com conhecimentos de outros anos, intensificar o nível de singularidade e criatividade de materiais derivados da cortiça.

\subsection{Uma matéria histórica}

A cortiça é uma matéria utilizada desde a pré-história. No Antigo Egito foram 
encontradas peças de cortiça e ornamentos em diversos objetos do quotidiano, sandálias, tampas de urnas, tampas de caixas e armazenamento de alimentos. Estava presencialmente em portas, armários, caixas e forros. Na Grécia antiga o material já era utilizado como vedante, tanto para vasilhas de azeite como de vinho: função de rolha (Mestre 2008, p.21).

A cortiça é um produto natural derivado do sobreiro (Quercus Saber L.nomenclatura botânica), uma árvore em grande abundância, que ocupa grande parte do território português, que possui um clima mediterrâneo favorável para a proliferação desta espécie. O montado, nome dado à região predominantemente ocupada por sobreiros, possui um ecossistema único onde não há chuva no verão, sendo muito seco e com grandes chances de ocorrerem incêndios. Passa pelo homem a responsabilidade de cuidar desse meio onde habitam os sobreiros, ajudando no controle da vegetação que lá existe, pois é através das profundas raízes que se torna possível encontrar humidade no solo, bem como manter vivas as espécies que se alimentam dessa vegetação- gerar com isso uma simbiose, um ecossistema.

Os sobreiros são "as árvores cortiça". São árvores que aguentam árduos períodos de seca pois têm também a capacidade de reduzir a transpiração das suas folhas fechando os poros delas.

Podemos retirar cortiça de um sobreiro por aproximadamente entre 150 e 200 anos. Isso equivale a 13 - 18 extrações de cortiça durante a vida de uma árvore, dada a necessidade de 9 anos para se dar uma nova tiragem manual, realizada pelos corticeiros (Mestre, 2011). O descortiçamento realiza-se durante o verão, período em que a cortiça apresenta maior elasticidade que resulta da expansão das células.

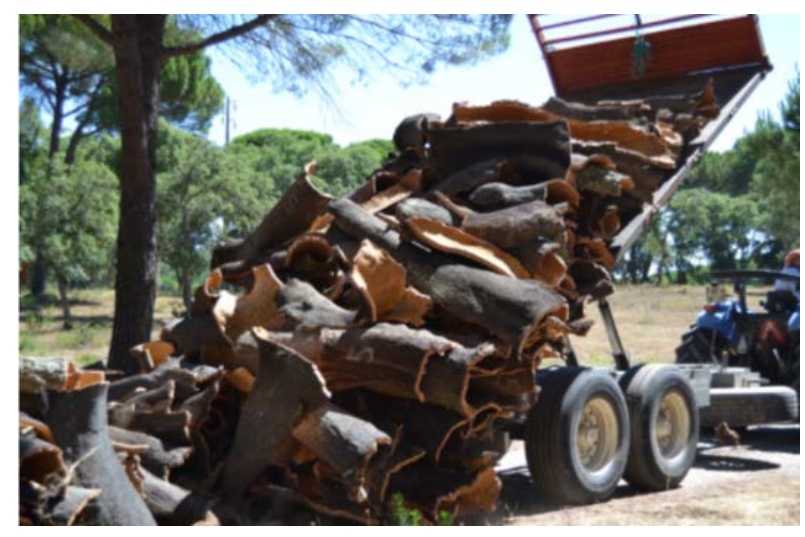

Figura 1 - Carregamento de cortiça recém tirada, Montado, Portugal, 2014. Fonte: Workshop Cork 2014.

]

As diversas actividades humanas praticadas ao longo dos séculos na Reserva Natural da Serra da Malcata levaram à destruição de grande parte da vegetação arbórea autóctone da zona: bosques de Quercus suber (sobreiro) característicos das bacias da Ribeira da Meimoa e Rio Côa, no Centro e Norte de Portugal.

Segundo Meirelles(2005),

“a recuperação da vegetação potencial é uma das prioridades da política de Área Protegida [Áreas Protegidas de Portugal continental], pelo que se decidiu avaliar a capacidade de restauração das comunidades climatófilas a partir da regeneração natural da espécie supra mencionada não 
intervencionados em anos recentes (tipo de intervenção designado por 'Dinâmica Natural') e os geridos com 'Fogo' e 'Corte'”.

\subsection{Propriedades da cortiça}

É essencial perceber que através da estrutura celular da cortiça conseguimos tirar partido dos seus atributos e verificar o que a torna uma matéria-prima leve, elástica, comprimível, impermeável a líquidos e gases, com uma excelente capacidade de isolamento térmico e acústico, de combustão lenta, com elevada resistência ao atrito e, por fim, hipoalergênica.

Essa categorização da cortiça permite estabelecer comparações com outros materiais, tais como o vidro, a cerâmica ou os metais e enumerar as suas propriedades químicas, físicas e mecânicas, estabelecendo uma relação causa-efeito entre as vantagens já referidas.

É importante ainda destacar que um conhecimento pormenorizado do material, pode permitir aplicações mais complexas na área do design, seja, por exemplo, no revestimento de embarcações, transportes coletivos, como vagões, ou equipamento desportivo, produtos de design em geral, como mobiliário, aplicações têxteis e inclusive na indústria aeroespacial e em equipamentos bélicos.

A cortiça tem em média 40 milhões de células por $\mathrm{cm}^{3}$, e uma rolha para vinho tem aproximadamente 800 milhões de células. As células da cortiça apresentam uma quantidade mínima de material sólido e uma quantidade máxima de matéria gasosa, essencialmente formada por ar atmosférico, isento de dióxido de carbono. Mais de $50 \%$ do volume de uma rolha é ar, o que a torna muito pouco densa.

As camadas intracelulares das células da cortiça são constituídas por cinco partes: duas partes de celulose, as quais revestem as câmaras celulares cheias de ar; uma parte de suberina, matéria dura e que torna a cortiça impermeável; uma parte de ceras, matéria dura e que atua também na impermeabilidade; uma parte de lenha, que permite manter a estrutura e rigidez necessárias ao material.

São as camadas de suberina e ceras em atuação simultânea que conferem à cortiça a elasticidade característica deste material (Corticeira Amorim, 2014.)

\subsection{Importância ambiental}

A cortiça é uma fonte de energia renovável, não tóxica e durável. Ela reúne propriedades mecânicas e físicas que se encontram dispersas em outros materiais. É também grande responsável pela fixação de $\mathrm{CO}_{2}$ na atmosfera (Gil, 1998 apud Mestre, 2011).

\subsection{Importância econômica}

A exportação de produtos de cortiça representa cerca de $3 \%$ do total das exportações portuguesas e ronda os 900 milhões de euros anuais, o que faz de Portugal o maior exportador de cortiça e produtos de cortiça do mundo. É a única atividade econômica que torna Portugal como líder mundial. A gestão dos montados de sobro com a exploração da cortiça gera também importantes rendimentos a nível local e regional que permite fixar e manter o emprego no mundo rural (Campos, 2009 apud Mestre, 2011).

Segundo relatórios da Associação Portuguesa da Cortiça (APCOR) de 2007, Portugal estava envolvido em aproximadamente $67 \%$ das exportações desse material em nível mundial, o que faz com que seja o líder desse setor. O destino principal da exportação da cortiça é para a indústria das rolhas, que absorve $69 \%$ de toda a produção. Os países que mais consomem a matéria são a França e os Estados Unidos da América, 
com a produção de espumante. A segunda maior indústria que consome esse material é a da construção civil, utilizando-o para a fabricação de pavimentos, isolantes, revestimentos e superfícies (Mestre, 2011).

\subsection{A indústria da cortiça}

O setor da cortiça representa um papel fundamental na atividade socioeconômica. Outros setores de produtos sintéticos são concorrentes com o da cortiça, especialmente com produtos de isolamento ou de construção, porém, as propriedades dessa matéria natural ainda não conseguiram ser replicadas de forma ecológica ou sustentável (Mestre, 2011).

A indústria da cortiça é localizada maioritariamente perto dos locais de extração do material, porém os setores de trabalho do material dividiram-se por zonas. A maior parte de aglomerados negros de cortiça é produzida no sul de Portugal. Os granulados e os concentrados são no Norte, o que exige uma movimentação constante da mataria pelo país.

A indústria corticeira é ainda dividida em dois setores, os das grandes-empresas e o das pequenas-empresas, que são afetadas pelo grande consumo do material por parte das maiores. As pequenas-empresas, porém, não deixam de ser muito importantes pois são elas que asseguram a flexibilidade do sistema e explorando de outras formas o material com uma abordagem diferenciada (Mestre, 2011).

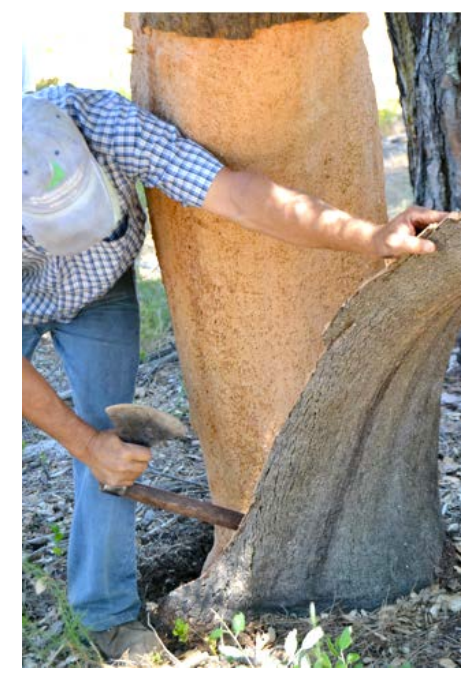

Figura 2 - Descortiçamento, Montado, Portugal, 2014.

Fonte: Workshop Cork 2014.

\subsection{Aplicações}

Para trabalhar a cortiça como matéria-prima torna-se essencial que esta seja selecionada e catalogada. Existem vários grupos em que esta se enquadra consoante a sua seleção. É de extrema relevância perceber a espessura do material e os seus defeitos e qualidades para que exista um patamar de qualidade com diferentes preços e mercados. A ampliação da experimentação do uso da cortiça como matéria-prima é de grande relevância é $100 \%$ eco-eficiente. O desbaste do material para originar novos objetos de design deixa resíduos que, por sua vez, são triturados formando os aglomerados. Estes aglomerados podem originar dois tipos distintos de matéria: aglomerados expandidos ou aglomerados compósitos, os compósitos variam a sua 
composição consoante a substância que se aplique na cortiça. Por fim, o pó restante da trituração da cortiça é o principal combustível para as máquinas que atuam sobre todo esse processo.

Após a preparação do material, os vários mercados podem, finalmente, atuar sobre o material. Ana Mestre1 é uma das pioneiras no projeto com cortiça e na aplicabilidade do material. Foi também responsável pelos primeiros estudos sensoriais relacionados com a cortiça e com as suas características (Mestre, 2011; Mestre, 2008). Outro grande projeto de destaque deu-se na ESAD Matosinhos, no Porto onde foram demostrados os grandes valores da cortiça aplicados na joalheria contemporânea (ESAD, 2nd Skin - Cork Jewellery. E.S.D.A. e D.D.L.A. Cultural, 2007: Porto).

Estes dois exemplos de projeto, e observando o panorama crescente da exploração dos usos da cortiça em Portugal, demonstram a grande potencialidade em explorar a cortiça como um meio e como um recurso no desenvolvimento de projetos em design.

Em Portugal existem dois tipos de estudos relacionados à cortiça. $O$ de pesquisa acadêmica, realizado em universidades e com caráter exploratório, e o de desenvolvimento realizado por fábricas e indústrias, em laboratórios e voltado para a melhoria e descoberta de novas utilizações e novos produtos para o mercado. Existem muitas patentes aliadas à cortiça que pertencem a empresas e até ao Estado. Essas patentes impedem que muitas das utilizações identificadas para a cortiça sejam implantadas no mercado, o que exige a substituição desse material por outros de baixo valor e qualidades semelhantes, levando ao não desenvolvimento desse setor.

Assiste-se a uma progressiva substituição de rolhas de cortiça por outros modos de vedação de garrafas de vinho. O cenário que se delineia é de que o uso as rolhas de cortiça serão progressivamente restritas a vinhos de qualidade superior. Com issso abre-se ampliação do uso de cortiça em outros tipos de produto. Tal situação configura uma situação de oportunidade para o design com utilização dos variados produtos de cortiça. Um desafio e um estímulo para a inovação em design.

\subsubsection{Aplicações de produtos da cortiça no design}

\section{Cortiça Natural}

A cortiça natural é utilizada após a sua retirada dos sobreiros. Após a tiragem em pranchas, as estas são deixadas em repouso para que ganhem uma forma plana e possam ser melhor utilizadas pela indústria. As utilizações da matéria neste estado referem-se maioritariamente na criação das rolhas de cortiça, dos discos de cortiça e no acabamento de varas de pesca (Gil, 1998 apud Mestre, 2011).

\section{Placas de Aglomerado Negro Densificadas}

As Placas de Aglomerado Negro Densificadas são resultantes de um processo completamente natural (sem adição de colas ou outros materiais sintéticos).

Este processo envolve a compressão das placas de aglomerado negro expandidas a

\footnotetext{
${ }^{1}$ Ana Mestre, designer e pesquisadora. É licenciada em Design Industrial pelo IADE (Lisboa, 2001), mestre em Tecnologias Renováveis pela Universidade Nova (Lisboa, 2005) e doutorada pela Delft University of Technology. É fundadora do Susdesign - Design for Sustainability Studio, Consultancy, Education, and Research e da marca Corque Design. Atua na investigação da cortiça e da sustentabilidade e possui um papel ativo no desenvolvimento de novos produtos com base nesses conceitos.
} 
uma determinada temperatura e pressão. Através deste processo há um maior controle na densidade do material, um melhor acabamento das placas e um maior preço reduzido de manufatura (Gil, 1999 apud Mestre, 2011).

\section{Aglomerados compósitos com Resinas Naturais ou Sintéticas}

Os compósitos aglomerados que mais se conhecem e são utilizados na indústria são os aglomerados brancos. São feitos através da reutilização da cortiça que é desperdiçada nos setores de transformação da cortiça virgem. É um excelente meio de reutilização dos desperdícios de cortiça. Estes aglomerados são feitos através de adição de aglutinantes sintéticos para formar uma mistura de granulados e resina. Em muitas indústrias, essas misturas são realizadas em moldes, o que permite, após a secagem, laminar o material.

Estas lâminas de Aglomerados Compósitos são utilizadas com diferentes propósitos, desde a construção civil (revestimentos e isolamentos) passando pela indústria automotiva e aeronáutica e pelo setor dos produtos de casa (mobiliário e acessórios) (Gil, 1999 apud Mestre, 2011).

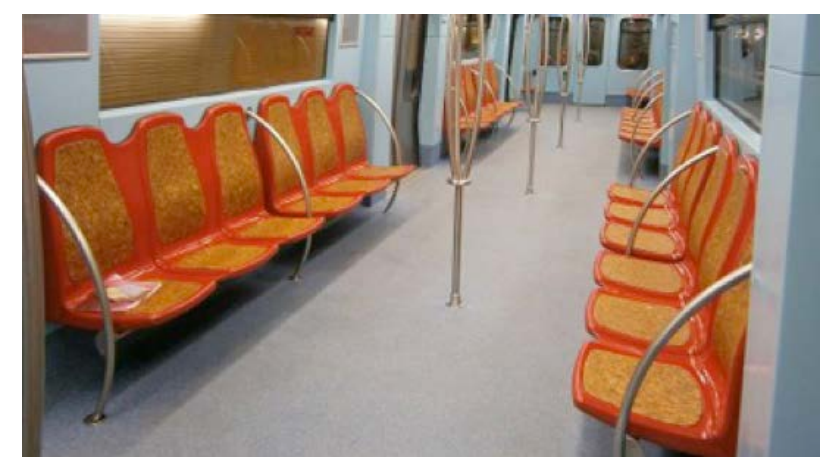

Figura 3 - Metropolitano de Lisboa (remodelação), Portugal. Fonte: TVL.pt. Disponível online em: http://tvl.pt/2013/03/22/metro-de-lisboa-com-carruagens-a-americana/

\section{Gel de Cortiça}

O Gel de Cortiça é uma composição de silicone com granulados de cortiça natural. São vulgarmente utilizados e produzidos para fitas de punho de bicicletas pois as excelentes capacidades da cortiça em absorvem impactos, torna os punhos mais confortáveis, resistentes ao calor, à água e ao suor e é elástico (Mestre, 2011). Também podem se encontrar as mesmas fitas em raquetes de ténis e badminton sendo um produto, portanto, com uma utilização vocacionada para o desporto.

\section{Tecidos de Cortiça e Papel}

São conhecidos como "pele de cortiça" ou "cork skin" e são fabricados a partir de rolos de cortiça aglutinada e compensada que são laminados, formando as folhas desse material.

Este material tem uma longa duração e a textura da cortiça, permitindo, inclusive, escolher entre uma grande variedade de estampagens, padrões e cores. São muito utilizados no design de moda e na confeç̧ão de malas, sapatos, guarda-chuvas, bolsas, carteiras e souvenirs variados. 


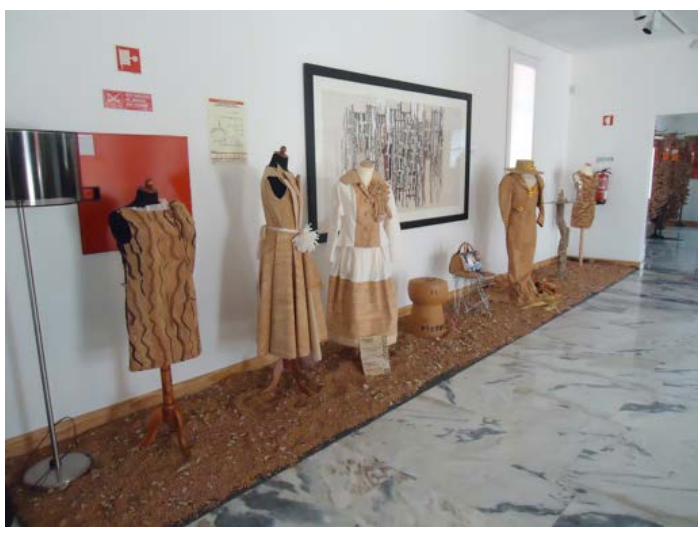

Figura 4 - Exposição FICOR, Observatório do Sobreiro e da Cortiça, Coruche, Portugal, 2015. Fonte: Workshop Cork 2015.

\section{Lã de Cortiça}

É utilizada em diferentes aplicações mas as mais comuns são em revestimentos e estofamentos de sofás e colchões. Algumas das propriedades mais relevantes da aplicação deste material são: a ausência de toxinas, capacidade de compressão e descompressão, durabilidade, leveza, impermeabilidade e isolação. A lã de cortiça é ainda citada como capacitada de inibir distúrbios no sono bem como pode ser utilizada em associação com outros tratamentos de saúde alternativos (Mestre, 2011).

\subsubsection{Aplicações de produtos da cortiça na construção civil}

\section{Granulados}

São obtidos através da moagem dos desperdícios da cortiça (principalmente da indústria das rolhas) e são utilizados na sua maioria para a criação dos aglomerados. São ainda utilizados na construção civil, onde são misturados com cimento ou em preenchimento de espaços vazios, transmitindo as suas propriedades acústicas e térmicas para o material e para a estrutura. São ainda utilizados para a construção de tijolos mais leves e também com as propriedades mencionadas acima (Gil, 1999 apud Mestre, 2011).

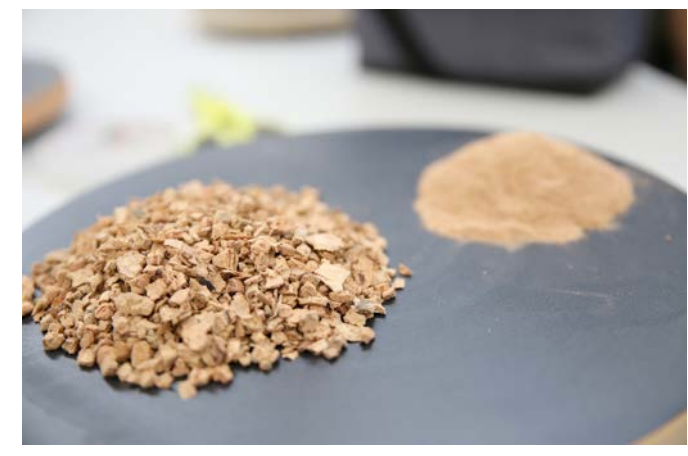

Figura 5 - Granulado de Cortiça. Exposição CORK, new uses in architecture. FAUL, Portugal, 2015. Fonte: Workshop Cork 2015.

\section{Aglomerado Negro Expandido}

Estes aglomerados são feitos através de um processo, aglutinando os granulados da cortiça virgem. $O$ processo de fabricação passa pela compressão dos granulados por 
uma autoclave que serve também como molde. Enquanto são comprimidos são também submetidos à uma grande temperatura e pressão. $O$ resultado são pranchas de Aglomerado Negro Expandido, que são um produto natural e de origem vegetal, sem agentes sintéticos e com excelentes características ecológicas. Este material é utilizado na industria principalmente como isolamento anti-vibração e para isolamento anti-som (Gil, 1999 apud Mestre, 2011).

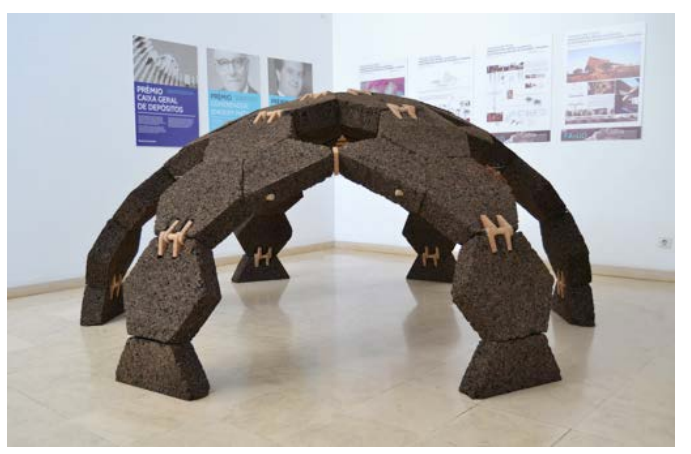

Figura 6 - "Cork Dome". Cúpula de aglomerado negro expandido. CORK, new uses in architecture. FAUL, Portugal, 2014.

Fonte: Workshop Cork 2014.

\section{Aglomerado Compósito com Borracha (RubberCork ou CorkRubber)}

O RubberCork ou CorkRubber é um componente criado a partir de aglomerados de cortiça e borrachas sintéticas. Estes materiais são misturados e prensados a quente em uma estrutura rotativa e cilíndrica, de modo a formar uma massa homogénea que poderá ser cortada em placas ou posta em novos moldes que poderão originar blocos. Esta técnica de aglutinação permite combinar a compressão e a elasticidade da cortiça com a resistência a gases e à água e a flexibilidade da borracha. Este material é vulgarmente utilizado em juntas, pavimentação e isolação de vibrações (Gil, 1999 apud Mestre, 2011). É importante referir que novas misturas utilizando pneus gastos e sem usos estão a ser obtidas, podendo assim, reutilizar um material que leva centenas de anos a se degradar na natureza.

\section{Aglomerados Compósitos Aglutinados com Desperdícios de embalagens Tetrapack}

Este material inclui na sua composição combinação de de fibras e partículas de desperdícios de pacotes Tetrapack que são aquecidos em simultâneo com a cortiça aglomerada e comprimidos. Os resultados obtidos desta mistura são um material com alta capacidade de aplicação e com as mais várias características que é utilizado como revestimentos, isolamento anti-vibração, pavimentação (com características antielectroestáticas) (Gil, 2005).

\section{Polímeros Compósitos de Cortiça}

São obtidos através da junção de cortiça em pó com polipropileno, poliestireno e poliuretano em gel. Estes Polímeros Compósitos têm uma excelente estabilidade, são resistentes à água e são melhores isolantes sonoros. Possuem uma grande rigidez e graças têm uma resistência ao fogo semelhante à dos aglomerados de cortiça.

Estes Polímeros apresentam grandes capacidades de exploração no design de pavimentos e nas construções. Tem ainda diversas aplicações nas áreas dedicadas ao conforto e no campo médico (Gil, 1998 apud Mestre,. 2011). 


\section{Plástico Reforçado de Fibras de Cortiça}

Um material que abre as portas para as aplicações na área industrial, como nos trens, barcos, ônibus e na aeronáutica. Um exemplo da utilização deste material e que já está a ser comercializado é o revestimento de caiaques (Mestre, 2011) pois as propriedades da cortiça os tornam mais leves e ajudam na resistência à água para não afundar.

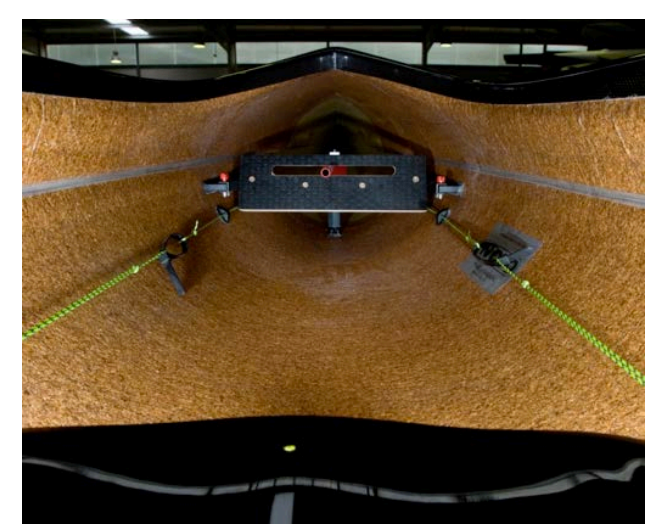

Figura 7 - Caiaque revestido em cortiça. Fonte: APCOR - Associação Portuguesa da Cortiça. Disponível em: http://www.apcor.pt/. Verificado em 07 mai. 2016

Sanduíche de Aglomerados de Cortiça com placas laminadas de MDF, madeira, alumínio ou outros

Este processo e revestimento de material como o MDF, a madeira ou o alumínio com aglomerados de cortiça permitem aplicações mais personalizadas no campo da decoração e do mobiliário. As relevâncias da utilização deste material partem da diferença estética e ecológica e das capacidades anti-vibráticas da cortiça, ajudando a isolar o som.

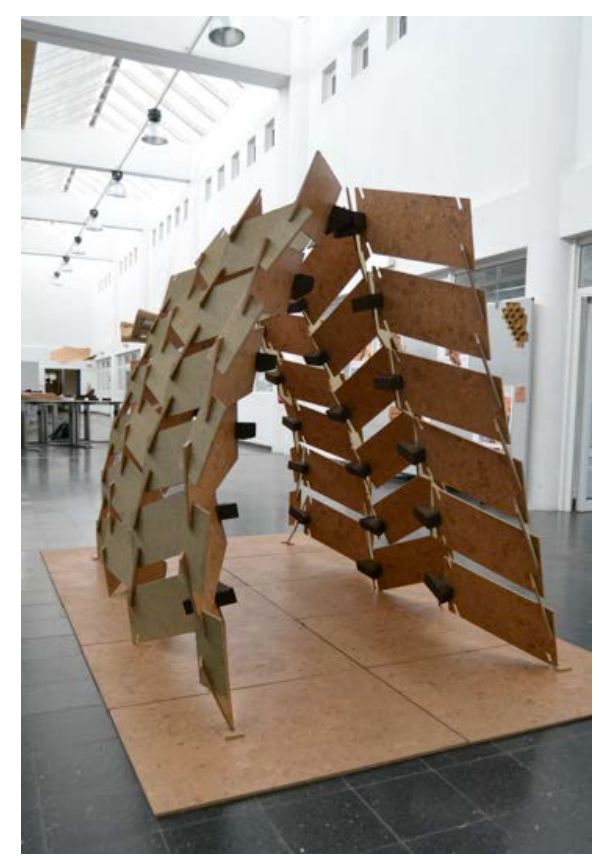

Figura 8 - "Cork Blades. Estrutura de MDF revestida em cortiça. CORK, new uses in architecture. FAUL, Portugal, 2015. Fonte: Workshop Cork 2015. 


\subsubsection{Outras aplicações de produtos da cortiça}

\section{Aglomerados de Cortiça em Pó sem adição de colas}

Este é um processo de utilização da cortiça em pó em simultâneo com outras matérias, sem a adição de colas. O processo inicia-se com a despolimerização e em seguida, a matéria é submetida a um processo de desumidificarão, até atingir os valores necessários. Por fim, o calor por pressão é iniciado, onde vários componentes da cortiça são polimerizados, funcionando como elementos aglutinantes do novo material que se forma (Gil, 1994 apud Mestre, 2011).

\section{Sanduíches de Aglomerado Negro com Fibras Naturais e outros materiais}

Este material é derivado de um processo de compressão de painéis de aglomerado negro expandido com outros materiais. Alguns materiais já utilizados na indústria são as fibras de coco e o neopreno (Gil, 1998 apud Mestre, 2011).

\section{Pó de cortiça}

Esta matéria é o resíduo restante das fábricas de transformação da cortiça. Sem muita utilidade, era muito frequente transformá-lo em uma mistura sintética através da junção de termo plásticos, porém com os avanços da Engenharia, descobriu-se que se torna uma importante fonte de energia para as fábricas e, por isso, é reaproveitada para criar energia, reduzindo o consumo de outras matérias químicas e poluentes e comprovando um ciclo de reaproveitamento máximo do material.

\section{CONCLUSÃO}

A síntese do estudo aqui apresentada intenta difundir a amplitude do potencial de aplicação da cortiça e estimular os designers a explorarem as suas possibilidades de experimentação e adoção em produtos na área do design. Os estudos que tenham por alvo materiais frequentemente utilizados no design face às novas tecnologias permitem alargar e multiplicar os seus empregos. A cortiça, porém, é um material que ainda não tem tido o seu potencial explorado pelos designers, a despeito de já haverem sido identificadas características que ensejam seus variados modos de aplicação, tanto estrutural, como sob forma de revestimentos, assim tendo a sua versatibilidade tecnológica. A cortiça alia uma possibilidade de expressão cultural a excelentes propriedades químicas, físicas, sensoriais e estéticas.

Justifica-se, assim, a ampliação da utilização da cortiça na área do design, pois seus atributos só têm a contribuir para um melhoramento dos projetos cuja aplicação seja adequada. É importante referir também que as características estéticas da cortiça também têm a contribuir para os valores ambientais de um material com um ciclo de vida longo e muito rentável. Contudo, o conhecimento sobre este material é ainda limitado mesmo nos países que o produzem, maioritariamente Portugal e Espanha. Mostra-se oportuna a exploração deste recurso tão rico e que cresce num meio com características muito particulares e restritas.

As múltiplas possibilidades beneficiamento de aparas de cortiças ampliam as oportunidades de serem enfrentados novos desafios tecnológicos, estéticos e de hápticos deste material como insumo.

O estímulo que é proposto aos designers é o da exploração das qualidades da 
cortiça como matéria-prima em diversificadas áreas do design, reforçando o seu cariz ecológico e sustentável da economia e do projeto.

\section{REFERÊNCIAS}

APCOR. Videoteca. Disponível na internet por http em: < http://www.apcor.pt/mediacenter/multimedia/videoteca/> . Acesso em 19 mai. 2016

A Arte da Cortiça. Porto: Corticeira Amorim, 2014. Disponível online em: <http://www.amorim.com/xms/files/Documentacao/Brochura_Arte_Cortica_PT_Small.pdf>. Acesso em 24 abr. 2016

Cork, new uses in architecture. Página do facebook do projeto. Disponível online em: < facebook.com/corkworkshop/>. Acesso em 12 mar 2016

Corquedesign. Disponível online em: <http://www.corquedesign.com/>. Consultado em 15 mar. 2016

ESAD Matosinhos. 2nd Skin - Cork Jewellery. Porto: Cultural, 2007

Feira internacional de cortiça em Coruche. In: CORUCHE/PORTUGAL. 2015. Disponível em: http://www.ficor.com.pt/

FIALHO, J. F. Apresentação oral em sala. Unidade curricular de Materiais. Realizado na Faculdade de Arquitetura da Universidade de Lisboa. 2013

GIL, Luís. Cortiça — Produção, Tecnológias e Aplicação. Lisbon: INETI, 1998.

MEIRELLES, C. et al. Estudo da Regeneração Natural das Espécies Arbóreas

Autóctones na Reserva Natural da Serra da Malcata. Lisboa: Silva Lusitânia v.13 n.2 dez. 2005.

Mestre Ana et. al. Cork for Sustainable Product Design. Ciência e Tecnologia dos Materiais. volume 23. 2011 Disponível em:

http://repositorio.Ineg.pt/bitstream/10400.9/1383/1/corkfor\%20sustainable10\%20(3).pdf>.

MESTRE, Ana. Design Cork for Future, Innovation and Sustainability. Lisboa:

Susdesign, 2008. Acesso em 10 fev. 2016

Susdesign. Design for Sustainability, Research, Consultancy and Education. Disponível online em: <http://www.susdesign.org/>. Consultado em 15 mar. 2016. 